https://helda.helsinki.fi

\title{
Akkermansia muciniphila and its role in regulating host functions
}

\author{
Derrien, Muriel
}

2017-05

Derrien, M , Belzer , C \& de Vos , W M 2017 , ' Akkermansia muciniphila and its role in regulating host functions ' , Microbial Pathogenesis , vol. 106 , pp. 171-181 . https://doi.org/10.1016/j.micpath.2016.0

http://hdl.handle.net/10138/236401

https://doi.org/10.1016/j.micpath.2016.02.005

unspecified

publishedVersion

Downloaded from Helda, University of Helsinki institutional repository.

This is an electronic reprint of the original article.

This reprint may differ from the original in pagination and typographic detail.

Please cite the original version. 
Review

\title{
Akkermansia muciniphila and its role in regulating host functions
}

\author{
Muriel Derrien ${ }^{\text {a, }}{ }^{\text {, }}$, Clara Belzer ${ }^{\mathrm{b}}$, Willem M. de Vos ${ }^{\mathrm{b}, \mathrm{c}, * *}$ \\ a Danone Nutricia Research, Avenue de la Vauve, 91767 Palaiseau, France \\ ${ }^{\mathrm{b}}$ Laboratory of Microbiology, Wageningen University, Wageningen, The Netherlands \\ ${ }^{\mathrm{c}}$ Immunobiology Research Program, Department of Bacteriology and Immunology, Haartman Institute, University of Helsinki, Helsinki, Finland
}

\section{A R T I C L E I N F O}

\section{Article history:}

Received 1 November 2015

Received in revised form

7 February 2016

Accepted 9 February 2016

Available online 11 February 2016

\section{Keywords:}

Akkermansia muciniphila

Metabolic disorder

Akkermansia-host interaction

Pre-clinical and clinical studies

\begin{abstract}
A B S T R A C T
Akkermansia muciniphila is an intestinal bacterium that was isolated a decade ago from a human fecal sample. Its specialization in mucin degradation makes it a key organism at the mucosal interface between the lumen and host cells. Although it was isolated quite recently, it has rapidly raised significant interest as A. muciniphila is the only cultivated intestinal representative of the Verrucomicrobia, one of the few phyla in the human gut that can be easily detected in phylogenetic and metagenome analyses. There has also been a growing interest in A. muciniphila, due to its association with health in animals and humans. Notably, reduced levels of $A$. muciniphila have been observed in patients with inflammatory bowel diseases (mainly ulcerative colitis) and metabolic disorders, which suggests it may have potential anti-inflammatory properties. The aims of this review are to summarize the existing data on the intestinal distribution of $A$. muciniphila in health and disease, to provide insight into its ecology and its role in founding microbial networks at the mucosal interface, as well as to discuss recent research on its role in regulating host functions that are disturbed in various diseases, with a specific focus on metabolic disorders in both animals and humans.
\end{abstract}

๑) 2016 Elsevier Ltd. All rights reserved.

\section{Contents}

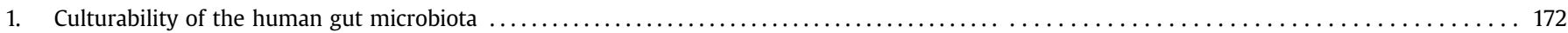

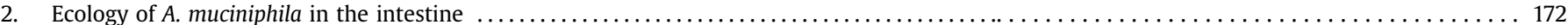

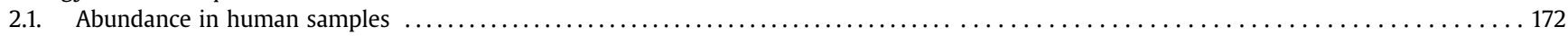

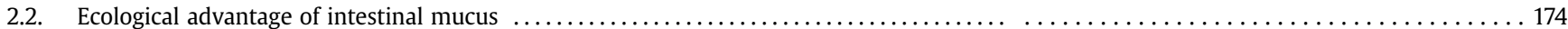

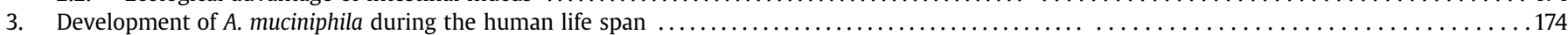

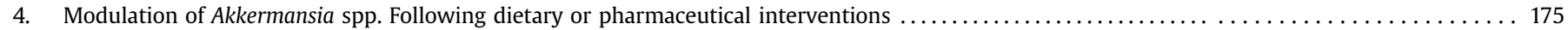

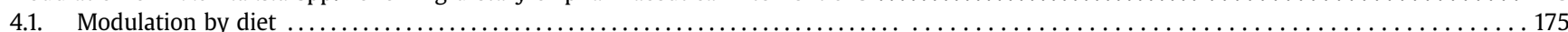

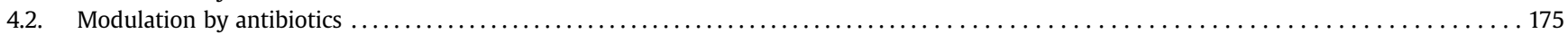

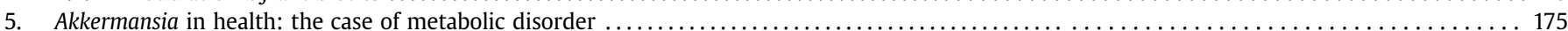

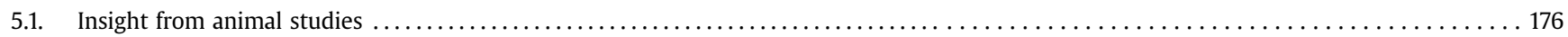

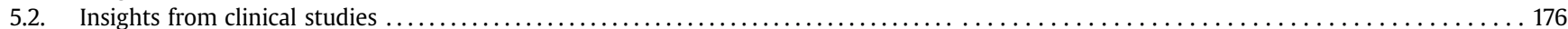

Abbreviations: DSS, dextran sulfate sodium; FISH, fluorescent in situ hybridization; HFD, high fat diet; FODMAP, fermentable oligosaccharides disaccharides; monosaccharides and polyols IBD, inflammatory bowel disease; LPS, Lipopolysaccharide; MGS, metagenomic species; qPCR, quantitative PCR; IgA, immunoglobulin A; T-RFLP, terminal-restriction fragment length polymorphism; T2D, type 2 diabetes.

* Corresponding author.

** Corresponding author. Laboratory of Microbiology, Wageningen University, Wageningen, The Netherlands.

E-mail addresses: muriel.derrien@danone.com (M. Derrien),willem.devos@wur nl (W.M. de Vos). 


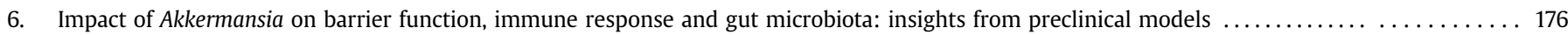

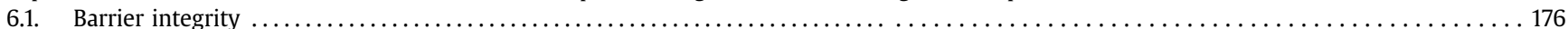

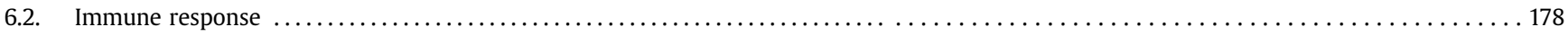

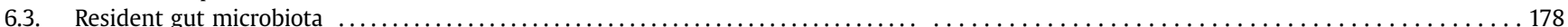

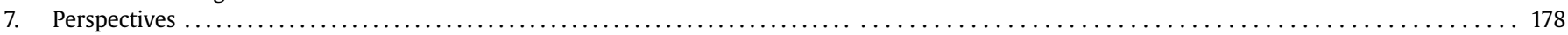

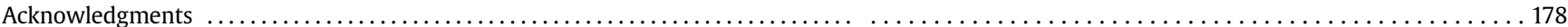

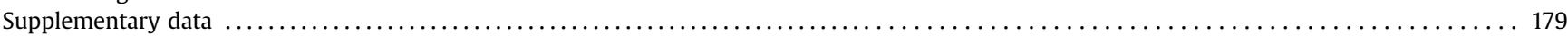

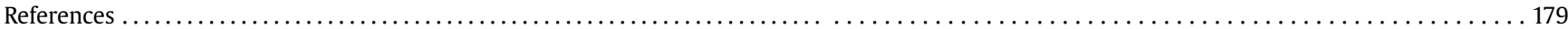

\section{Culturability of the human gut microbiota}

The human intestine is home to more than a thousand microbial species. A recent review pointed out that over 1000 microorganisms, belonging to Bacteria, Archaea and Eukarya, have been obtained in pure cultures [1]. In 1950, the study of intestinal bacteria was revolutionized by the development of an array of techniques for culturing strict anaerobes by Robert Hungate [2]. Prior to this, mostly only aerobic or facultative anaerobic bacteria could be isolated from intestinal samples. The use of strict anaerobic conditions according to the Hungate approach enabled the extensive characterization of the major intestinal microbes in the 1970s. Cultivation of most intestinal bacteria has been carried out using rich media, or semi-defined media with targeted carbon sources. In the late 1970s, Carl Woese discovered a third domain of life, Archaea, using a proposed universal phylogenetic marker, the 16S rRNA gene, that can be used as a signature of prokaryotic species [3]. This and the subsequent molecular revolution based on rapid sequencing methods have drastically changed the perception of microbial ecology, allowing for a more representative description of various ecosystems, and circumventing the need to cultivate bacteria in order to describe the community of a specific niche [3]. This has also emphasized that most of the sequences returned from profiling human intestinal microbiota samples are derived from microbes that have not yet been cultivated. In parallel, although there has been a decline in new cultivation approaches, there is an obvious renewal of interest in cultivating gut microbes. Indeed, obtaining bacteria in pure culture is complementary to molecular approaches since they provide information (e.g. physiology,

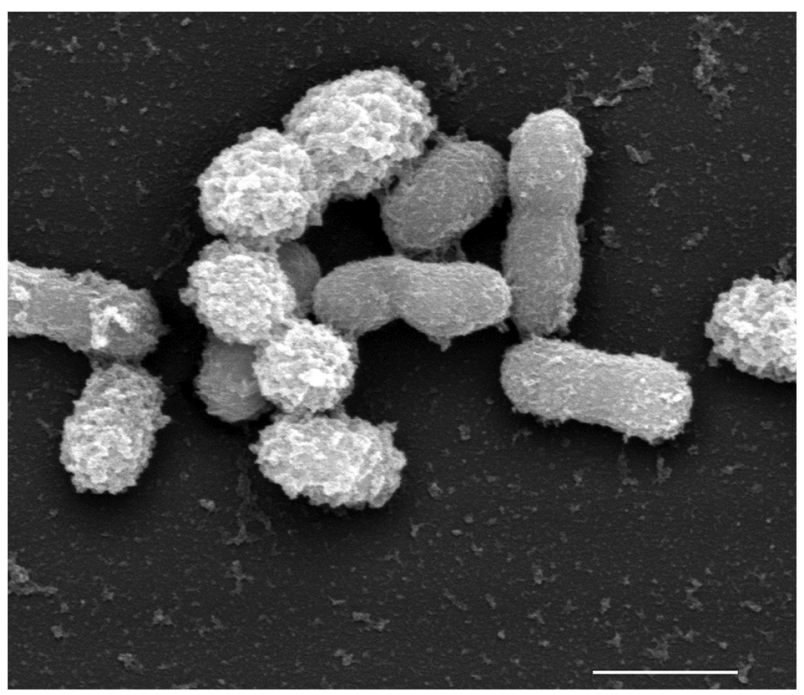

Fig. 1. Scanning electronic micrograph of Akkermansia muciniphila ATCC BAA-835 (Bar represents $1 \mu \mathrm{m}$. interaction with host and other bacteria) that molecular approaches do not. However, the direct use of genome sequencing from intestinal samples to characterize as yet uncultivated microorganisms, can also provide information on their genetic capacity to use specific nutrients [4,5]. As a major fraction of the gut microbial ecosystem has not yet been cultured, it is often regarded as being refractory to cultivation in the laboratory. Although that is probably true for some microbes that are either too dependent on the host or on other bacteria to grow, the use of defined medium combined with novel isolation strategies (such as culturomics) has nevertheless, led to the successful isolation of an increasing number of intestinal bacterial species [6-8]. A recent example of an organism that was refractory to in vitro isolation is Candidatus arthromitus (also known as segmented filamentous bacteria, or SFB) that is found abundantly in the intestinal tract of mice although not, or not all, in humans. Using a strategy that combines an SFB-host cell co-culturing system, SFB was first isolated in pure culture in 2015 [9]. Some examples of currently uncultivable bacteria from human microbiota that are frequently detected in human samples by sequencing technologies include members of the Candidate TM7 phylum and Cyanobacteria [5], as well as some genera of Clostridiales such as Oscillospira, neither of which have been obtained in pure culture, although indications for the sequence of their genomes have been obtained. A species that was successfully isolated is Akkermansia muciniphila (Fig. 1). Interestingly it was, and still is, the first intestinal microbial isolate of the phylum Verrucomicrobia. With its isolation came the awareness that this phylum is represented in the intestine. It was originally isolated from a fecal sample from a healthy Caucasian female in a specific medium that contained purified mucin as the sole carbon source, using the most probable number approach [10]. Mucin was chosen as a selective carbon source since it was hypothesized that microbes capable of utilizing these host-produced glycans as carbon sources are those that are located at the interface between the luminal bacteria and the host, a prediction that materialized with the discovery of A. muciniphila.

\section{Ecology of $A$. muciniphila in the intestine}

\subsection{Abundance in human samples}

Once isolated, it was important to quantify the amount of A. muciniphila cells within human stool samples in order to evaluate whether it is commonly present. It was originally determined that A. muciniphila accounted for more than $1 \%$ of the total microbiota using fluorescent in situ hybridization (FISH) and quantitative PCR (qPCR) [11,12]. Notably, at that time, FISH was also commonly used to quantify major bacterial taxa. Interestingly, it was observed that Akkermansia spp. could not be targeted by the classical EUB-338 I universal bacterial probe. Later, the wider availability of $16 \mathrm{~S}$ rRNA gene sequencing allowed for the detection of the genus Akkermansia in a large number of studies. When the 
Table 1

Overview of clinical studies (observational or interventional) related to metabolic disorder in which a differential Akkermansia abundance was observed.

\begin{tabular}{|c|c|c|c|c|c|c|}
\hline Target population & $\begin{array}{l}\text { Study } \\
\text { (observational or } \\
\text { intervention) }\end{array}$ & $\begin{array}{l}\text { Groups } \\
\text { (number of } \\
\text { individuals) }\end{array}$ & $\begin{array}{l}\text { Microbiota } \\
\text { analysis } \\
\text { approach }\end{array}$ & $\begin{array}{l}\text { Samples analysed } \\
\text { time }\end{array}$ & Akkermansia population & References \\
\hline Obese women & Observational & $\begin{array}{l}\text { Obese } \\
\text { women } \\
(\mathrm{n}=53)\end{array}$ & $\begin{array}{l}\text { Whole } \\
\text { shotgun } \\
\text { metagenomic }\end{array}$ & $\begin{array}{l}\text { Stool } \\
\text { One time point }\end{array}$ & $\begin{array}{l}\text { Negatively associated with markers for insulin resistance } \\
\text { or dyslipidaemia }\end{array}$ & [96] \\
\hline Elite athletes & Observational & $\begin{array}{l}\text { Elite athletes } \\
\text { high BMI } \\
(\mathrm{n}=40) \\
\text { Healthy } \\
\text { males Low } \\
\text { BMI } \leq 25 \\
(\mathrm{n}=23) \\
\text { Healthy } \\
\text { males high } \\
\text { BMI }(\mathrm{n}=23)\end{array}$ & $\begin{array}{l}16 \mathrm{~S} \\
\text { sequencing }\end{array}$ & $\begin{array}{l}\text { Stool } \\
\text { One time point }\end{array}$ & $\begin{array}{l}\text { Higher proportions in athletes and in low } \\
\text { BMI control group }\end{array}$ & {$[122]$} \\
\hline $\begin{array}{l}\text { Infants of overweight and } \\
\text { normal-weight mothers }\end{array}$ & Observational & $\begin{array}{l}\text { Lean } \\
(\mathrm{n}=16) \\
\text { Overweight } \\
\text { mothers } \\
(\mathrm{n}=26) \\
\text { Infants }(1,6 \\
\text { months) }\end{array}$ & $\begin{array}{l}\text { qPCR } \\
\text { FISH-FCM }\end{array}$ & $\begin{array}{l}\text { Stool } \\
\text { Infants }(1,6 \text { months })\end{array}$ & $\begin{array}{l}\text { Decreased prevalence in infants of normal-weight } \\
\text { mothers and of mothers with normal weight gain during } \\
\text { pregnancy }\end{array}$ & [98] \\
\hline $\begin{array}{l}\text { Lean and overweight } \\
\text { lactating women }\end{array}$ & Observational & $\begin{array}{l}\text { Lean women } \\
(\mathrm{n}=34) \\
\text { Overweight } \\
\text { women } \\
(\mathrm{n}=22)\end{array}$ & qPCR & $\begin{array}{l}\text { Breast milk (after } \\
\text { delivery, } 1 \text { and } 6 \\
\text { months later) }\end{array}$ & $\begin{array}{l}\text { Trend towards increased prevalence in breast milk ( } 1 \\
\text { month after delivery) from overweight mothers }\end{array}$ & [37] \\
\hline $\begin{array}{l}\text { Overweight and obese } \\
\text { adults }\end{array}$ & $\begin{array}{l}6 \text {-week calorie } \\
\text { restriction }(\mathrm{CR}) \text { and } \\
6 \text {-week follow up }\end{array}$ & $\begin{array}{l}\text { Overweight } \\
(\mathrm{n}=11) \\
\text { Obese } \\
(\mathrm{n}=38)\end{array}$ & qPCR & $\begin{array}{l}\text { Stool } \\
\text { Baseline (T0) } \\
\text { After CR }(\mathrm{T}=6 \\
\text { weeks) } \\
\text { After weight } \\
\text { stabilisation }(\mathrm{T}=12 \\
\text { weeks) }\end{array}$ & $\begin{array}{l}\text { At baseline, } \text { A. muciniphila MGS was inversely related to } \\
\text { fasting glucose, waist-to-hip ratio, and subcutaneous } \\
\text { adipocyte diameter Subjects with higher level of } \\
\text { A. muciniphila at baseline had greater improvement in } \\
\text { insulin sensitivity markers and other clinical parameters } \\
\text { after CR }\end{array}$ & {$[15]$} \\
\hline $\begin{array}{l}\text { Lean, overweight and obese } \\
\text { adults }\end{array}$ & Observational & $\begin{array}{l}\text { Lean } \\
(\mathrm{n}=10) \\
\text { Overweight } \\
(\mathrm{n}=10) \\
\text { Obese } \\
(\mathrm{n}=10)\end{array}$ & $\begin{array}{l}16 S \\
\text { sequencing }\end{array}$ & $\begin{array}{l}\text { Stool } \\
\text { One time point }\end{array}$ & Akkermansia negatively correlated with BMI & [95] \\
\hline $\begin{array}{l}\text { Lean, overweight and obese } \\
\text { children( } 4-5 \text { years })\end{array}$ & Observational & $\begin{array}{l}\text { Lean } \\
(n=20) \\
\text { Overweight, } \\
\text { obese } \\
(n=20)\end{array}$ & qPCR, T-RFLP & $\begin{array}{l}\text { Stool } \\
\text { One time point }\end{array}$ & Decrease in obese/overweight children & [92] \\
\hline Obese women & $\begin{array}{l}\text { 8-week of impact } \\
\text { of } 4 \mathrm{~g} \text { of Ephedra } \\
\text { sinica extract/day }\end{array}$ & $\begin{array}{l}\text { Obese } \\
\text { women } \\
(\mathrm{n}=7)\end{array}$ & $\begin{array}{l}16 \mathrm{~S} \\
\text { sequencing }\end{array}$ & $\begin{array}{l}\text { Stool } \\
2 \text { samples/subject } \\
\text { (before and after } \\
\text { Ephedra sinica } \\
\text { extract intake) }\end{array}$ & Positive association of Akkermansia with weight loss & [123] \\
\hline T2D and healthy individuals & Observational & $\begin{array}{l}\mathrm{T} 2 \mathrm{D}(\mathrm{n}=71) \\
\text { Healthy } \\
\text { controls } \\
(\mathrm{n}=74)\end{array}$ & $\begin{array}{l}\text { Whole } \\
\text { shotgun } \\
\text { metagenomic }\end{array}$ & $\begin{array}{l}\text { Stool } \\
\text { One time point }\end{array}$ & Increase in $\mathrm{T} 2 \mathrm{D}$ & [99] \\
\hline Overweight individuals & $\begin{array}{l}\text { 1-week fasting } \\
\text { program and 6- } \\
\text { week probiotic } \\
\text { intervention }\end{array}$ & $\begin{array}{l}\text { Overweight } \\
\text { adults } \\
(\mathrm{n}=13)\end{array}$ & qPCR & $\begin{array}{l}\text { Stool } \\
\text { Before fasting (T1) } \\
\text { During fasting (T2) } \\
\text { After 6-week } \\
\text { probiotic } \\
\text { intervention (T3) }\end{array}$ & Increase between $\mathrm{T} 1$ and $\mathrm{T} 3$ & [124] \\
\hline Obese individuals & $\begin{array}{l}\text { 16-week weight } \\
\text { reduction diet }\end{array}$ & $\begin{array}{l}\text { Obese } \\
\text { individuals } \\
(n=33)\end{array}$ & qPCR & $\begin{array}{l}\text { Stool } \\
\text { Before, during and } \\
\text { after intervention }\end{array}$ & Increase after weight reduction & [94] \\
\hline $\begin{array}{l}\text { Normal weight and } \\
\text { overweight pregnant } \\
\text { women ( } 24 \text { weeks) }\end{array}$ & Observational & $\begin{array}{l}\text { Normal } \\
\text { weight } \\
(\mathrm{n}=34) \\
\text { Overweight } \\
(\mathrm{n}=16)\end{array}$ & qPCR & $\begin{array}{l}\text { Stool } \\
\text { One time point }\end{array}$ & $\begin{array}{l}\text { No difference between normal and overweight Decrease } \\
\text { in excessive weight gain }\end{array}$ & [97] \\
\hline Adult women & Observational & $\begin{array}{l}\text { Lean } \\
(\mathrm{n}=17) \\
\text { Obese } \\
(\mathrm{n}=50)\end{array}$ & qPCR & $\begin{array}{l}\text { Stool } \\
\text { One time point }\end{array}$ & Trend to increase prevalence in lean individuals & [93] \\
\hline
\end{tabular}


Table 1 (continued)

\begin{tabular}{|c|c|c|c|c|c|c|}
\hline Target population & $\begin{array}{l}\text { Study } \\
\text { (observational or } \\
\text { intervention) }\end{array}$ & $\begin{array}{l}\text { Groups } \\
\text { (number of } \\
\text { individuals) }\end{array}$ & $\begin{array}{l}\text { Microbiota } \\
\text { analysis } \\
\text { approach }\end{array}$ & $\begin{array}{l}\text { Samples analysed } \\
\text { time }\end{array}$ & Akkermansia population & References \\
\hline $\begin{array}{l}\text { Lean, morbidly obese post- } \\
\text { gastric-bypass surgery } \\
\text { human subjects }\end{array}$ & Gastric bypass & $\begin{array}{l}\text { Normal } \\
\text { weight } \\
(\mathrm{n}=3) \\
\text { Morbidly } \\
\text { obese }(\mathrm{n}=3) \\
\text { Post-gastric- } \\
\text { bypass } \\
\text { surgery } \\
(\mathrm{n}=3)\end{array}$ & $\begin{array}{l}16 \mathrm{~S} \\
\text { sequencing }\end{array}$ & $\begin{array}{l}\text { Stool } \\
\text { One time point }\end{array}$ & $\begin{array}{l}\text { Increase after bariatric surgery } \\
\text { Low in obese }\end{array}$ & [85] \\
\hline $\begin{array}{l}\text { Normal glucose tolerance } \\
\text { (NGT), Prediabetes (PD) } \\
\text { and newly diagnosed } \\
\text { T2D subjects }\end{array}$ & Observational & $\begin{array}{l}\text { NGT }(n=44) \\
\text { Pre-DM } \\
(\mathrm{n}=64) \\
\text { T2D }(n=13)\end{array}$ & $\begin{array}{l}16 \mathrm{~S} \\
\text { sequencing }\end{array}$ & $\begin{array}{l}\text { Stool } \\
\text { One time point }\end{array}$ & Decrease in Pre-DM and T2D & [125] \\
\hline
\end{tabular}

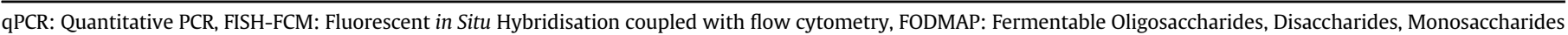
and Polyols, MGS: Metagenomic Species, T-RFLP: Terminal-Restriction Fragment Length Polymorphism, T2D: Type 2 Diabetes.

human gut microbiota was proposed to segregate into three distinct bacterial communities or enterotypes, Akkermansia spp. were found to occur in the enterotype in which Ruminococcus or Clostridiales were the main drivers [13]. Using a correlation network, Akkermansia was found to be positively associated with Gordonibacter as well as Ruminococcaceae, and negatively associated with Prevotella [13]. In two independent clinical studies (Danish and French cohorts), A. muciniphila was present in greater abundance in subjects with a high metagenome richness [14,15]. Moreover, in the French cohort, correlation networks of metagenomic species (MGS) including that of Akkermansia, were determined. Several MGS positively correlated with Akkermansia, including Methanobrevibacter smithii, the most abundant and prevalent methane producer, as well as members of the family Ruminococcaceae [15]. This could indicate that these bacteria have similarnutritional requirements or that they engage in crossfeeding.

In mono-colonised mice, Akkermansia is more prevalent in the colon than in the ileum [16]. This is supported by studies in conventional mice [17]. In an in vitro model involving three fermenters to mimic the human colonic environment, Akkermansia was not detected in the microbiota of the ascending colon, while it was detected in the transverse and descending colon compartments, with highest abundance in the transverse compartment $[18,19]$.

\subsection{Ecological advantage of intestinal mucus}

Intestinal mucus is composed of an inner layer devoid of bacteria and a thicker outer layer with commensal bacteria [20]. Its major components, mucins, are a source of nutrients for intestinal bacteria since it is composed of amino acids and oligosaccharides. Some bacteria possess the enzymatic machinery necessary for the breakdown of the mucins' oligosaccharide chains, which in turn, release fucose, galactose, $\mathrm{N}$-acetylglucosamine, $\mathrm{N}$-acetylgalactosamine, sialic acid, sulfate, and also di-sacharides and small oligosaccharides that can be further metabolized by the resident microbiota. Mucin degradation by commensal bacteria has been reviewed elsewhere [21,22]. Elegant experiments with nano-SIMS (stable isotope mass spectrometry) in combination with FISH showed that Akkermansia is among the first utilizers of labeled mucus on the mouse mucosa [23]. Mucin degradation offers an ecological advantage to bacteria that are dependent on dietary nutrients. Indeed, in the absence of dietary glycans, host-derived mucins represent a constant source of nutrients. This advantage would explain the diverse ecological habitats of Akkermansia spp. When we screened the databases available for the presence of
Akkermansia species it became apparent that this organism is commonly found in the intestines all over the animal kingdom [24]. Indeed, $A$. spp. have been detected in the intestines of various animals including rodents (references Table S1), but also donkeys [25], rabbits [26], Syrian hamsters [27] pythons [28], horses [29,30], pigs [31] and rock ptarmigans [32] amongst others. An interesting finding has been that its relative abundance increases in humans, mice, hamsters and snakes under conditions of caloric restriction (Table 1 and S1). This supports the suggestion of the existence of mucosal communities driven by A. muciniphila [24]. While these experiments do not exclude the possibility that there are other mucus utilizers, it is relevant to note that mucosal analysis showed A. muciniphila to be abundant in biopsies of healthy subjects but reduced in those of patients with Inflammatory Bowel Disease (IBD), who in contrast, had increased amounts of Ruminococcus gnavus [33]. Comparative biochemical analysis of the sialidases of these bacteria revealed marked differences consistent with a selfish phenotype of $R$. gnavus, while the A. muciniphila lifestyle was compatible with a phenotype that stimulates tropic chains [34].

\section{Development of $A$. muciniphila during the human life span}

The development of the intestinal A. muciniphila community with age has been investigated in several studies with subjects of different nationalities. In an early study, its development over a wide age-range was determined in infants (1, 6 and 12 months of age), adults (25-35 years of age) and the elderly (80-82 years of age) in a Finnish population. A. muciniphila was found to colonize the intestinal tract in early life and to achieve a level close to that observed in adults within a year [12,35]. A. muciniphila was more abundant in adults than in Finnish children less than one year old, as determined by qPCR and FISH. In the same study, the $A$. muciniphila levels were found to decline in elderly subjects [12]. In another study that compared the abundance of selected bacteria in breastfed Finnish and German infants at 6 months of age [36], the presence of bacteria resembling $A$. muciniphila was also detected at a very low concentration in breast milk $(<3$ log number of gene copies/ml of breast milk) [37] and in the microbiota of human breast tissue [38]. This could be attributed to the presence in breast milk of oligosaccharides that resemble mucin in composition and structure [21]. However, studies have indicated that $A$. muciniphila levels were higher in formula-fed as compared to breast-fed infants $[39,40]$.

A detailed comparison was made between the fecal microbiota of Italian centenarians (99-104 years), elderly (63-76 years) and young adults (25-40 years) using qPCR and a phylogenetic array approach. Notably, there was less $A$. muciniphila present in young 
adults compared to elderly subjects [41]. However, a slightly lower abundance of Akkermansia was observed in Chinese centenarians (100-108 years) compared to Chinese elderly subjects (80-92 years) [42]. These studies suggest that the evolution of Akkermansia communities with age may differ between populations and this warrants further investigation. However, care should be taken to interpret all the results of these different studies and populations as it has been shown that the levels of Bifidobacterium and Bacteroides spp., and to some extent also A. muciniphila Ievels, correlate with the fucosylation status, suggesting that the genotype of the host determines the colonization of mucus [43]. Moreover, the abundance of $A$. muciniphila in the human intestine may depend on body mass, mucus thickness and the immune status of the host. These factors are likely to change during a life time and also during or immediately prior to the onset of disease. Such changes might be expected to alter the A. muciniphila levels. Some studies in mice reported a decreased relative abundance of Akkermansia with age. In aging leptin deficient obese mice ( 16 versus 8 -week old mice), the level of Akkermansia decreased as glucose tolerance declined [44]. Interestingly, in immunodeficient Rag1-/- mice (lacking mature lymphocytes), the abundance of Akkermansia also decreased with age [45]. However, it should be emphasized that the translation of results from mouse models is continuously challenged [46] and it is has now been well established that the human and mouse microbiome only share small fraction of common metagenomic information [4].

\section{Modulation of Akkermansia spp. Following dietary or pharmaceutical interventions}

\subsection{Modulation by diet}

Various nutritional interventions, mainly in animal models, have been reported to affect the levels of Akkermansia spp in the intestine. In some cases, the administration of specific dietary components improved host health and also increased the Akkermansia population. Such compounds include polyphenols [19,47,48], fructo-oligosaccharide [49,50], conjugated linoleic acid [51], oat bran [52], type 2 resistant starch from high-amylose maize [53], fermentable oligosaccharides, disaccharides, monosaccharides and polyols (FODMAP) [54], whole grain barley [55] and polyamines [56,57], red pitaya [58] Bifidobacterium animalis subsp lactis LMG P-28149 [59], maize-derived non-digestible feruloylated oligo- and polysaccharides [60], amongst others. Interestingly, medicinal herbs (Flos Lonicera and fermented Rhizoma Atractylodis Macrocephalae) as well as fungi (Ganoderma lucidum) that are traditionally considered in Asian culture as medicine [61-63], also increased the proportion of Akkermansia with a concomitant beneficial effect on host metabolism. Akkermansia spp. were also reported to be increased upon consumption of pectin or guar gum only in rats fed a High Fat Diet (HFD) [64] or barley malt [55], but decreased in HFD supplemented with barley malt [55]. However, a decrease in the level of Akkermansia was observed in rats fed a HFD enriched in pectin or guar gum [64]. Several studies have reported a decrease in abundance of Akkermansia following HFD [65-67]. Recently, a diet enriched in heme (the pigment of red meat) was shown to increase the abundance of Akkermansia in mice $[17,24]$. Various reports describe the impact of pharmaceutical treatments on the intestinal level of Akkermansia. Metformin is a common antidiabetic drug and was found to increase the levels of Akkermansia spp. populations in mice both on a HFD and normal diet, while the growth of $A$. muciniphila was stimulated in Brain Heart Infusion broth supplemented with metformin [67,68]. Another widely used drug, the proton pump inhibitor omeprazole, was shown to decrease the abundance of Akkermansia spp. in mice
[69]. However, this has not been noted in a recent human study where the effect of proton pump inhibitors had some impact on bacteria other than Akkermansia [70].

\subsection{Modulation by antibiotics}

A major known stressor of the intestinal microbiota is the exposure to antibiotics. Although the impact on the microbiota is antibiotic-dependent, in both animals and humans, Akkermansia spp. was found to bloom after exposure to specific antibiotics. However, many studies are only based on 16S rRNA sequencing data and these do not provide a quantitative approach and hence it is not always clear whether Akkermansia spp. increase in number, or remain stable while the other members of the gut microbiota are severely impacted. An example is a recent study reporting that the use of tylosin boosted the relative abundance of Akkermansia in young mice [71]. In a more comprehensive study, on the basis of 16S rRNA gene sequencing, an enormously increased level of Akkermansia spp. (up to 80\%) was reported in two subjects treated with broad-spectrum antibiotic therapy [72]. As the subjects did not have gastrointestinal disorders, this indicates that these extreme numbers have no harmful effect on the human host. This unusual observation led to a further exploration of the absolute amount of Akkermansia present in the stool of these individuals by FISH, which confirmed the increase in relative and absolute abundance of Akkermansia in these adults. Although the Akkermansia strain responsible was not isolated in pure culture, its deduced genome based on metagenome analysis of an Akkermansiaenriched stool sample revealed high identity to the cultured strain, A. muciniphila $\mathrm{Muc}^{\mathrm{T}}\left[\right.$ [73]. The cultivated A. muciniphila strain Muc ${ }^{\mathrm{T}}$ culture appeared to be resistant to vancomycin and metronidazole [72]. Higher abundance of Akkermansia, together with lactic acid bacteria and other bacteria with unusual cell-envelopes, was also observed in the microbiota of adult volunteers exposed to therapeutic doses of vancomycin [74]. Similarly, an increase of Akkermansia was observed in one patient, reaching $6 \%$ of total bacteria, after 6 days of consumption of a $\beta$-lactam. However, the level of Akkermansia declined at the end of the 14- day consumption period $[75,76]$. The apparent vancomycin-resistance of $A$. muciniphila explains why vancomycin treatment resulted in an enrichment of Akkermansia in a NOD mouse model for type-1 diabetes [77].

\section{Akkermansia in health: the case of metabolic disorder}

Several studies reported a reduction in the abundance of A. muciniphila in various disorders and diseases in humans. The majority of these include intestinal diseases, such as IBD, as well as extra-intestinal diseases, such as autism, atopy or obesity and related diseases. In this section we will focus primarily on Akkermansia and metabolic disorder as most studies have addressed associations with this widely spreading aberration.

"Metabolic disorder" encompasses a variety of clinical manifestations, including central obesity and impaired fasting glucose, and ultimately increases the risk of developing T2D or cardiovascular diseases. In experimental models of obesity, increased intestinal permeability leads to metabolic endotoxemia, a migration of Gramnegative derived lipopolysaccharide (LPS) from the intestine into the circulation [78]. A great variety of association studies involving the intestinal microbiota and metabolic syndrome have been reported, with some contradictory results (for a review see [79]). Few studies showed an effect of fecal transplantations in germ-free or conventional animals $[80,81]$. Moreover, in a pioneering human fecal microbiota transplantation study, individuals with metabolic syndrome were infused with microbiota from a lean donor or their own microbiota. After 6 weeks, an improvement in insulin 
sensitivity was observed only in the lean donor treatment group and this was associated with the increase of a phylotype related to the butyrate producer Eubacterium hallii in the small intestinal mucosa [82]. This study supports the therapeutic potential of manipulating the gut microbiota for treatment of metabolic syndrome, and more specifically, for promoting insulin homeostasis in human.

\subsection{Insight from animal studies}

Recently, it was established that the intestinal Akkermansia abundance decreased in various knock-out or diet-induced mouse models that develop obesity or other signs of metabolic disorder. No less than 25 studies are reported (Table S1). These include studies that reported a lower abundance of Akkermansia in mice that were leptin deficient $[49,66]$ or fed a HFD $[66,71,83]$ and which were all obese or had T2D-like symptoms. Moreover, induced weight loss through gastric bypass surgery has been shown to lead to increased fecal numbers of Alistipes spp., Proteobacteria and Verrucomicrobia in the mouse and this was associated with immediate amelioration of glucose metabolism [84]. This is reminiscent of an earlier bypass study in obese humans where increased levels of Akkermansia among others, were reported in fecal samples [85]. While these studies are indicative of an association with Akkermansia, only a limited number of interventions have been described and provide direct support for the role of $A$. muciniphila in preventing metabolic disorders. In a seminal study, it was found that the daily administration of live cells of the A. muciniphila type strain $\left(10^{8} \mathrm{CFU} /\right.$ day $)$ for four weeks could counteract the deleterious metabolic features of a HFD diet in mice [66]. Remarkably, this administration of $A$. muciniphila prevented not only weight gain, but also restored epithelial integrity (mucus thickness) that was disturbed by HFD treatment, counteracted metabolic endotoxemia (serum LPS), and improved the metabolic profile [66]. This impact was only observed when viable A. muciniphila was administered, suggesting that metabolically active bacteria were required. The positive impact of $A$. muciniphila on metabolic syndrome features was subsequently reproduced in independent studies in various parts of the world using different experimental designs. In a metabolic feeding study, mice were first fed with a HFD for four weeks, followed by daily gavage of $A$. muciniphila $\left(4.10^{8} \mathrm{cfu} / \mathrm{day}\right)$ for six weeks, resulting in improved glucose tolerance and metabolic endotoxemia. However, a daily dose greater than $4.10^{7}$ live cells of $A$. muciniphila is necessary to improve the impaired glucose tolerance [67]. Of great interest was the additional observation that this A. muciniphila treatment also increased the number of T-reg and globlet cells in the gut, in line with observed immune signaling and increased mucus production. In another recent study, a mouse strain prone to obesity (AxB19) was used to investigate the impact of $A$. muciniphila inoculation on metabolic parameters [86]. Male AxB19 mice were fed with viable or heat killed $A$. muciniphila for one week followed by the high fat and high sucrose diet for 4-weeks, with concomitant $A$. muciniphila gavage $\left(10^{9} \mathrm{cfu} /\right.$ day). After five weeks of gavage, a significant decrease of various metabolic disorder parameters was observed, including body weight, body fat and insulin resistance among others [86]. Finally, Chevalier et al. inoculated live A. muciniphila $\left(2.10^{8} \mathrm{cfu} / \mathrm{day}\right)$ into germ-free mice conventionalized with microbiota from cold-exposed mice for 21 days. Notably the co-inoculation of $A$. muciniphila with the cold microbiota prevented the transferable increase in intestinal glucose absorption that was observed when the inoculum consisted of the cold-microbiota alone [87].

Overall, these observational and interventional studies suggest a role for $A$. muciniphila in the improvement of glucose- insulin homeostasis, reduction of fat accumulation and body weight, and-importantly, this was reproduced by different laboratories and with different experimental designs. While the mouse studies are convincing, some recent rat studies reported conflicting data. An increased abundance of Akkermansia was found in rats on a HFD supplemented with barley compared to the HFD control, while a low fat diet supplemented with barley led to a lower abundance of Akkermansia [88]. Similarly, an increased abundance of Akkermansia was reported in rats on a HFD [89-91]. The different outcomes are likely the effects of environmental and genetic factors. Moreover, these animal model experiments call for human trials with A. muciniphila to further study causality in a real life situation.

\subsection{Insights from clinical studies}

In clinical studies (Table 1), the abundance of Akkermansia is generally decreased in individuals with metabolic impairments, such as obese children [92] and adults (trend) [93]. Others show negative correlations between Akkermansia spp. and markers of metabolic disorder [94,95]. Variability between studies can be due to several factors including microbiota, host andmucin production amongst others. In a recent study, using quantitative metagenomics, A. muciniphila was found to be negatively associated with serum total and LDL cholesterol in obese Danish women. Moreover, a negative correlation was observed between dietary fat intake and its fecal abundance [96]. In a large observational study of a Danish cohort that consisted of obese and lean individuals, subjects with a high metagenome richness were found to be healthier than individuals with low metagenome richness. Furthermore, A. muciniphila was present in greater abundance in the former group [14]. Recently, these findings were reproduced in a French cohort consisting only of obese and overweight individuals [15]. The relationship between gut microbiota, metabolic syndrome and diet intake before and after a 6-week calorie restriction intervention was also investigated [15]. A. muciniphila MGS negatively correlated with fasting glucose, waist-to-hip ratio, and subcutaneous adipocyte diameter. Interestingly, individuals who harbored more $A$. muciniphila at baseline exhibited a better metabolic profile including improved insulin sensitivity [15]. In addition, Akkermansia spp. were less prevalent in women who gained more weight during pregnancy in a Spanish cohort [97]. Surprisingly, in a Finnish cohort, infants of overweight mothers harbored Akkermansia more frequently than infants of normal-weight mothers [98]. While a large study of Chinese subjects found that Akkermansia was more abundant in T2D patients compared to healthy controls [99], the antidiabetic drug metformin was recently reported as a confounding factor [100] and it has been shown that A. muciniphila can be stimulated by metformin [68]. Therefore, the high abundance of Akkermansia in these individuals could be an indirect effect of taking the drug. Support for this explanation stems from another study with Chinese adults where Akkermansia was found to be lower in pre-diabetic and newly diagnosed T2D patients [85]. Thus, it is tempting to speculate that metformin may also have an indirect effect on host metabolism via A. muciniphila, which could open new avenues to understanding the potential beneficial effect of metformin in T2D.

\section{Impact of Akkermansia on barrier function, immune response and gut microbiota: insights from preclinical models}

\subsection{Barrier integrity}

Compromised barrier function is the basis for many diseases 
varying from IBD to metabolic syndrome. One of the mouse models for IBD that targets intestinal barrier function include mice treated with dextran sulfate sodium (DSS). In some studies Akkermansia was found to increase markedly after DSS treatment [101-104], while in other studies this was not observed [105]. One could speculate that the thickness of the mucus layer and the observed low-grade inflammation in the DSS mice may negatively influence A. muciniphila colonization. Support for the beneficial effect of Akkermansia on colitis derives from the observation that extracellular vesicles from $A$. muciniphila were found to protect against the DSS-induced phenotype [105]. In most human studies a depletion of $A$. muciniphila is observed in IBD mucosa and in fecal samples from ulcerative colitis patients $[33,106]$. However, some other studies do not show this effect, but a technical bias cannot be excluded as the $A$. muciniphila may have a special spatial location in fecal samples [107].

The intestinal barrier plays a crucial role by spatially protecting the intestinal cells from the luminal bacteria through the turnover of mucus (synthesis and shedding), production of secretory immunoglobulin A (IgA) via immune exclusion, and secretion of antimicrobial peptides and proteins, mostly in the ileum, by Paneth cells [108]. Intestinal mucus is composed of an inner layer devoid of bacteria and a thicker outer layer with commensal bacteria [20]. Its major components, mucins, are a source of nutrients for intestinal bacteria since it is composed of amino acids and oligosaccharides. Some bacteria possess the enzymatic machinery necessary for the breakdown of the mucins' oligosaccharide chains, which in turn release fucose, galactose, N-acetylglucosamine, N-acetylgalactosamine, sialic acid, sulfate, and also di-sacharides and small oligosaccharides that can be further metabolized by the resident microbiota. Mucin degradation by commensal bacteria has been reviewed elsewhere [21,22]. As Akkermansia is specialized in mucin degradation, it is expected that its variation in the intestine might be associated with the amount of mucin present, although other bacteria are also involved in mucin degradation [21,22]. In rodents on a diet with or without prebiotics (arabinoxylans, inulin), Akkermansia abundance (as measured by FISH) positively correlated with the level of mucins in the cecum [109]. Earle et al., using imaging methods, observed a bloom of the Akkermansia population in mice following a depletion of microbiotaaccessible carbohydrates, resulting in a thinner mucus layer in the distal colon [110]. Recently, a study described the enrichment of Akkermansia in mice on a heme-enriched diet, and its depletion in mice fed with heme and a cocktail of broad-spectrum antibiotics (ampicillin, neomycin and metronidazole). The reduction of Akkermansia abundance following antibiotic treatment was accompanied by a reduction in the expression of the gene Muc2 encoding the major mucin of the colonic mucus in colonic tissues, as well as reduced mucolysis [111]. Indeed, besides being able to degrade mucins, Akkermansia was also found to simulate mucin production $[67,68]$. Hence, Akkermansia has not only the capacity to degrade mucins, but also to stimulate mucin synthesis, illustrative of an autocatalytic process. Regardless of whether its capacity to degrade mucins or stimulate their production depends on mucus thickness, the impact of

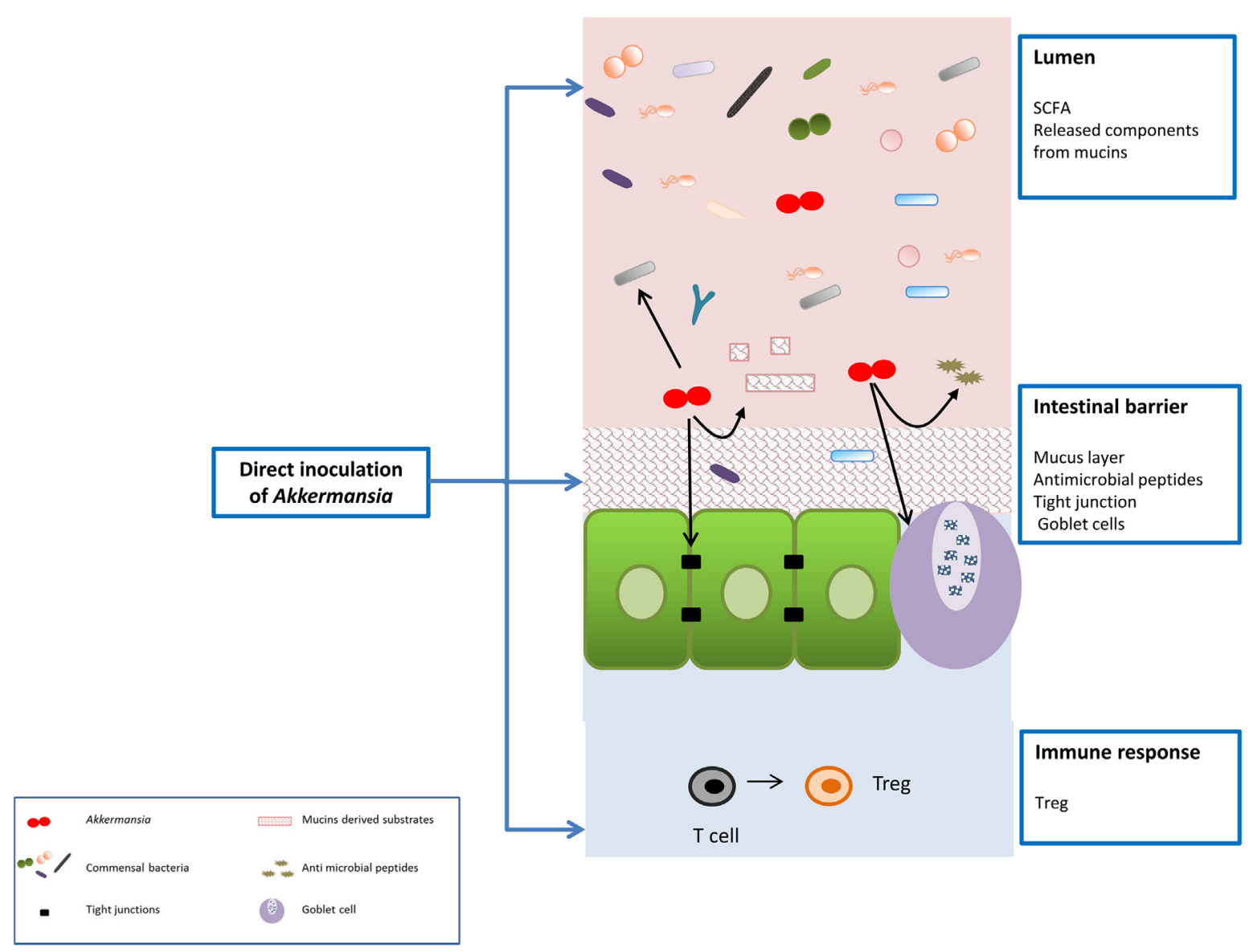

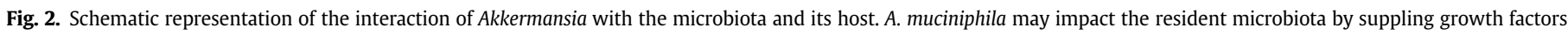
released from mucin degradation. A. muciniphila interacts with its host by strengthening the intestinal barrier, or by modulating mucin turnover and immune responses. 
the resident microbiota on mucin turnover in the gut merits further investigation.

\subsection{Immune response}

The first inoculation study with $A$. muciniphila involved a 7-day follow-up after a single inoculation of germ-free (GF) mice [16]. Subsequently, the host's transcriptional responses were determined in the small and large intestine. Although the normal behavior of a bacterium cannot be accurately mimicked in GF models, in which competition for niche and substrates is lacking, the study nevertheless highlighted the preferential niche of A. muciniphila in the colon, and the potential communication with host, with emphasis on immune signaling. Recently, the impact of A. muciniphila metabolites on the transcriptome of mouse ileal organoids was determined, with SCFA, notably propionate, as controls [112]. Both propionate alone, and metabolites produced from the grown culture, could induce pathways involved in lipid metabolism, growth, and immune response, confirming the previous experiment [22]. In addition to the mucus layer, antimicrobial peptides and the immune system are factors that maintain homeostasis. Mice fed a HFD with daily gavage of Akkermansia, showed enhanced production of the antimicrobial peptide Reg $3 \gamma$ in the colon, and slightly in the ileum [66]. This was not observed in the group fed with heat-killed Akkermansia. Secretory IgA is essential to maintain the luminal bacteria under control, and to keep the homeostasis at mucosal surfaces (see [113-115] for recent reviews). Recently, the microbiota was studied from discordant twins for Kwashiorkhor, a form of malnutrition that results from protein deficiency [116]. It was hypothesized that IgA would target the microbiotas of the undernourished and the healthy twin differently. To test this hypothesis, viable bacteria were isolated from a pair of discordant Malawian twins. Interestingly, Akkermansia was the major IgA-targeted bacterium in the healthy twin child, while members of Enterobacteriaceae were the major IgAtargeted bacteria in the undernourished child. Direct inoculation of live A. muciniphila with one other selected bacterium, Clostridium scindens prevented lethality in mice, and reduced the sloughing of epithelial cells compared to mice colonized with a consortia of IgAtargeted bacteria from the undernourished child, and fed with a diet mimicking the Malawian diet [116]. Interestingly, no increase of IgA was observed following a 4-week A. muciniphila gavage with HFD [66]. These results indicate that $A$. muciniphila is actively communicating to the host immune system and is in line with earlier findings that its administration stimulated the proliferation of anti-inflammatory regulatory T cells in mice [67].

Recently, Reunanen and colleagues examined the effect of live A. muciniphila on in vitro colonic cell lines (HT-29 and Caco2). Interestingly, A. muciniphila was able to adhere to the epithelium and strengthen the intestinal barrier. Notably, it induced a weak pro-inflammatory response (measured by IL-8 release) compared to a strain of $E$. coli K12 [117]. The intimate relationship of A. muciniphila and the host immune system is exemplified in the recent study from Zhang, where mice mutated in gene Rag1 (Rag1 -/-), which lack mature lymphocytes, exhibit a notable increase of Akkermansia according to the results of $16 \mathrm{~S}$ sequencing [45]. It is also worth mentioning that $A$. muciniphila has been associated with increased inflammation in a mouse model of a simplified microbiota with a Salmonella typhimurium infection [118]. The unexpected outcome from these experiments may relate to the use of GF mice that have a strongly compromised mucus barrier function prior to microbial colonization. Remarkably, it was found that $A$. muciniphila did not bind as effectively to mucus as a very active mucus-binder such as the probiotic Lactobacillus rhamnosus GG that is decorated with a mucus binding protein
$[117,119]$. Another recent study, however, showed mucus binding of the type strain of $A$. muciniphila as well as isolates from healthy and IBD patients, indicating that experimental conditions may determine the strength of the binding [120].

\subsection{Resident gut microbiota}

The potential modulation of the resident gut microbiota following A. muciniphila intake has also been investigated in three of the four mouse studies described [66,86,87] in which A. muciniphila cells were gavaged into mice. While no significant modulation of the gut microbiota was detected after daily gavage of $10^{8} \mathrm{cfu}$ Akkermansia/day for four weeks [66], it was reported in two studies that some shift occurred between the two major phyla, Bacteroidetes (increased) and Firmicutes (decreased) following a 5week gavage of $10^{9} \mathrm{cfu}$ Akkermansia/day [86], and following inoculation of live $A$. muciniphila $\left(2.10^{8} \mathrm{cfu} /\right.$ day $)$ for 21 days in germ-free mice conventionalized with microbiota from cold-exposed mice [87]. Notably an increase of Bifidobacterium was reported. Apart from the different doses used in studies, other variations included the methodology used, the culturing of cells and other factors. As discussed above, it is likely that administration of Akkermansia impacts the mucosal microbiota and its networks. In conclusion, all of these studies highlight that $A$. muciniphila communicates with host, exhibits potential anti-inflammatory responses, promotes barrier integrity and potentially modulates resident gut microbiota (Fig. 2). However, additional work is needed to understand the association of Akkermansia and inflammation in some disturbed conditions, notably in humans.

\section{Perspectives}

In summary, overall there are consistent findings related to decreased abundance of Akkermansia in metabolic disorder in both preclinical and clinical studies. The few interventional studies have reported a beneficial impact on host metabolism, strongly indicating a direct involvement of Akkermansia. However, some opposing effects have been reported, suggesting that further research should be carried out to investigate the relationship between Akkermansia and host metabolism. The presence of A. muciniphila in the upper intestine could be of importance for health in later life, because the microbial colonization of the mucosal layer by $A$. muciniphila can enable associations with other beneficial microbes, leading to a stable mucosal colonization throughout life. Moreover, a host with no or very low levels of A. muciniphila might therefore have a strong and specific response toward A. muciniphila derivatives given that they can be quite different from other microbial signatures in the gut. Possibly, the strong effects of $A$. muciniphila treatment are due to its phylogenetic distinctness within the intestinal microbiota. As this A. muciniphila is the only cultivated representative of a whole phylum, it has many proteins that are typically and solely expressed by this organism, with no homologues within the microbiome. A total of eight different species in the genus Akkermansia have been identified [121], supporting the unexplored Akkermansia diversity within the human gut microbiome. To date, only one A. muciniphila strain, the type strain $\left(\mathrm{Muc}^{\mathrm{T}}\right.$ ), is available in public culture collections. However, new isolates from humans and other animals are to be reported and may indicate how this unique mucolytic symbiont has adapted to its host.

\section{Acknowledgments}

This research was partly supported by ERC Advanced Grant 250172 - MicrobesInside from the European Research Council, the 
Netherlands Organization for Scientific Research (Spinoza Award and SIAM Gravity Grant 024.002.002) and the Finland Academy of Sciences (141130). MD is appointed by Danone Nutricia Research. We deeply acknowledge Anne Neville for revising the manuscript as well as Timothy Swartz for helpful discussions.

\section{Appendix A. Supplementary data}

Supplementary data related to this article can be found at http:// dx.doi.org/10.1016/j.micpath.2016.02.005.

\section{References}

[1] M. Rajilić-Stojanović, W.M. de Vos, The first 1000 cultured species of the human gastrointestinal microbiota, FEMS Microbiol. Rev. 38 (2014) 996-1047.

[2] R. Hungate, The anaerobic mesophilic cellulolytic bacteria, Bacteriol. Rev. 14 (1950) 1-49.

[3] C.R. Woese, G.E. Fox, Phylogenetic structure of the prokaryotic domain: the primary kingdoms, Proc. Natl. Acad. Sci. U. S. A. 74 (1977) 5088-5090.

[4] H.B. Nielsen, M. Almeida, A.S. Juncker, S. Rasmussen, J. Li, S. Sunagawa, et al., Identification and assembly of genomes and genetic elements in complex metagenomic samples without using reference genomes, Nat. Biotechnol. 32 (2014) 822-828.

[5] S.C. Di Rienzi, I. Sharon, K.C. Wrighton, O. Koren, L.A. Hug, B.C. Thomas, et al., The Human Gut and Groundwater Harbor Non-photosynthetic Bacteria Belonging to a New Candidate Phylum Sibling to Cyanobacteria, 2013.

[6] J.C. Lagier, F. Armougom, M. Million, P. Hugon, I. Pagnier, C. Robert, et al. Microbial culturomics: paradigm shift in the human gut microbiome study, Clin. Microbiol. Infec 18 (2012) 1185-1193.

[7] J.-C. Lagier, S. Edouard, I. Pagnier, O. Mediannikov, M. Drancourt, D. Raoult, Current and past strategies for bacterial culture in clinical microbiology, Clin. Microbiol. Rev. 28 (2015) 208-236.

[8] J.-C. Lagier, P. Hugon, S. Khelaifia, P.-E. Fournier, B. La Scola, D. Raoult, The rebirth of culture in microbiology through the example of culturomics to study human gut microbiota, Clin. Microbiol. Rev. 28 (2015) 237-264.

[9] P. Schnupf, V. Gaboriau-Routhiau, M. Gros, R. Friedman, M. Moya-Nilges, G. Nigro, et al., Growth and host interaction of mouse segmented filamentous bacteria in vitro, Nature 520 (2015) 99-103.

[10] M. Derrien, E.E. Vaughan, C.M. Plugge, W.M. de Vos, Akkermansia muciniphila gen. nov., sp. nov., a human intestinal mucin-degrading bacterium, Int. J. Syst. Evol. Microbiol. 54 (2004) 1469-1476.

[11] M. Derrien, M.C. Collado, K. Ben-Amor, S. Salminen, W.M. de Vos, The mucin degrader Akkermansia muciniphila is an abundant resident of the human intestinal tract, Appl. Environ. Microbiol. 74 (2008) 1646-1648.

[12] M.C. Collado, M. Derrien, E. Isolauri, W.M. de Vos, S. Salminen, Intestinal integrity and Akkermansia muciniphila, a mucin-degrading member of the intestinal microbiota present in infants, adults, and the elderly, Appl. Environ. Microbiol. 73 (2007) 7767-7770.

[13] M. Arumugam, J. Raes, E. Pelletier, D. Le Paslier, T. Yamada, D.R. Mende, et al., Enterotypes of the human gut microbiome, Nature 473 (2011) 174-180.

[14] E. Le Chatelier, T. Nielsen, J. Qin, E. Prifti, F. Hildebrand, G. Falony, et al, Richness of human gut microbiome correlates with metabolic markers, Nature 500 (2013) 541-546.

[15] M.C. Dao, A. Everard, J. Aron-Wisnewsky, N. Sokolovska, E. Prifti, E.O. Verger et al., Akkermansia muciniphila and improved metabolic health during a dietary intervention in obesity: relationship with gut microbiome richness and ecology, Gut 65 (3) (2016 Mar) 426-436, http://dx.doi.org/10.1136/gutjnl2014-308778.

[16] M. Derrien, P. Van Baarlen, G. Hooiveld, E. Norin, M. Müller, W. de Vos, Modulation of mucosal immune response, tolerance, and proliferation in mice colonized by the mucin-degrader Akkermansia muciniphila, Front. Microbiol. 2 (2011), http://dx.doi.org/10.3389/fmicb.2011.00166.

[17] G.A. Preidis, N.J. Ajami, M.C. Wong, B.C. Bessard, M.E. Conner, J.F. Petrosino, Composition and function of the undernourished neonatal mouse intestinal microbiome, J. Nutr. Biochem. 26 (2015) 1050-1057.

[18] P. Van den Abbeele, C. Grootaert, M. Marzorati, S. Possemiers, W.E. Verstraete, P. Gérard, et al., Microbial community development in a dynamic gut model is reproducible, colon region specific, and selective for Bacteroidetes and Clostridium Cluster IX, Appl. Environ. Microbiol. 76 (2010) 5237-5246.

[19] R.A. Kemperman, G. Gross, S. Mondot, S. Possemiers, M. Marzorati, T. Van de Wiele, et al., Impact of polyphenols from black tea and red wine/grape juice on a gut model microbiome, Food Res. Int. 53 (2013) 659-669.

[20] M.E.V. Johansson, M. Phillipson, J. Petersson, A. Velcich, L. Holm, G.C. Hansson, The inner of the two Muc2 mucin-dependent mucus layers in colon is devoid of bacteria, Proc. Natl. Acad. Sci. U. S. A. $105(2008)$ 15064-15069.

[21] L. Tailford, E. Crost, D. Kavanaugh, N. Juge, Mucin glycan foraging in the human gut microbiome, Front. Genet. 6 (2015).

[22] M. Derrien, M.W.J. van Passel, J.H.B. van de Bovenkamp, R. Schipper, W. de
Vos, J. Dekker, Mucin-bacterial interactions in the human oral cavity and digestive tract, Gut Microbes 1 (2010) 254-268.

[23] D. Berry, B. Stecher, A. Schintlmeister, J. Reichert, S. Brugiroux, B. Wild, et al., Host-compound foraging by intestinal microbiota revealed by single-cell stable isotope probing, Proc. Natl. Acad. Sci. U. S. A. 110 (2013) 4720-4725.

[24] C. Belzer, W.M. de Vos, Microbes inside - from diversity to function: the case of Akkermansia, ISME J. 6 (2012) 1449-1458.

[25] X. Liu, H. Fan, X. Ding, Z. Hong, Y. Nei, Z. Liu, et al., Analysis of the gut microbiota by high-throughput sequencing of the V5-V6 regions of the 16S rRNA gene in donkey, Curr. Microbiol. 68 (2014) 657-662.

[26] B. Zeng, S. Han, P. Wang, B. Wen, W. Jian, W. Guo, et al., The bacterial communities associated with fecal types and body weight of rex rabbits, Sci. Rep. 5 (2015).

[27] K. Sonoyama, R. Fujiwara, N. Takemura, T. Ogasawara, J. Watanabe, H. Ito, et al., Response of gut microbiota to fasting and hibernation in Syrian hamsters, Appl. Environ. Microbiol. 75 (2009) 6451-6456.

[28] E.K. Costello, J.I. Gordon, S.M. Secor, R. Knight, Postprandial remodeling of the gut microbiota in Burmese pythons, ISME J. 4 (2010) 1375-1385.

[29] C. Rodriguez, B. Taminiau, B. Brevers, V. Avesani, J. Van Broeck, A. Leroux, et al., Faecal microbiota characterisation of horses using 16 rdna barcoded pyrosequencing, and carriage rate of clostridium difficile at hospital admission, BMC Microbiol. 15 (2015) 181

[30] M.C. Costa, H.R. Stämpfli, E. Allen-Vercoe, J.S. Weese, Development of the faecal microbiota in foals, Equine Vet. J. (2015) n/a-n/a.

[31] A. Kanengoni, M. Chimonyo, T. Tasara, P. Cormican, A. Chapwanya, B. Ndimba, et al., A comparison of faecal microbial populations of South African Windsnyer-type indigenous pigs (SAWIPs) and large white $\times$ landrace $($ LW $\times$ LR) crosses fed diets containing ensiled maize cobs, FEMS Microbiol. Lett. 362 (2015).

[32] K. Ushida, T. Segawa, S. Tsuchida, K. Murata, Cecal bacterial communities in wild Japanese rock ptarmigans and captive Svalbard rock ptarmigans, J. Vet. Med. Sci. (2015) advpub.

[33] C.W. Png, S.K. Linden, K.S. Gilshenan, E.G. Zoetendal, C.S. McSweeney, L.I. Sly, et al., Mucolytic bacteria with increased prevalence in IBD mucosa augment in vitro utilization of mucin by other bacteria, Am. J. Gastroenterol. 105 (2010) 2420-2428.

[34] L.E. Tailford, C.D. Owen, J. Walshaw, E.H. Crost, J. Hardy-Goddard, G. Le Gall, et al., Discovery of intramolecular trans-sialidases in human gut microbiota suggests novel mechanisms of mucosal adaptation, Nat. Commun. 6 (2015).

[35] J. Cheng, T. Ringel-Kulka, I. Heikamp-de Jong, Y. Ringel, I. Carroll, W.M. de Vos, et al., Discordant temporal development of bacterial phyla and the emergence of core in the fecal microbiota of young children, ISME J. (2015).

[36] Ł. Grześkowiak, M.-M. Grönlund, C. Beckmann, S. Salminen, A. von Berg, E. Isolauri, The impact of perinatal probiotic intervention on gut microbiota: double-blind placebo-controlled trials in Finland and Germany, Anaerobe 18 (2012) 7-13.

[37] M.C. Collado, K. Laitinen, S. Salminen, E. Isolauri, Maternal weight and excessive weight gain during pregnancy modify the immunomodulatory potential of breast milk, Pediatr. Res. 72 (2012) 77-85.

[38] C. Urbaniak, J. Cummins, M. Brackstone, J.M. Macklaim, G.B. Gloor, C.K. Baban, et al., Microbiota of human breast tissue, Appl. Environ. Microbiol. 80 (2014) 3007-3014.

[39] M.B. Azad, T. Konya, H. Maughan, D.S. Guttman, C.J. Field, R.S. Chari, et al., Gut microbiota of healthy Canadian infants: profiles by mode of delivery and infant diet at 4 months, CMAJ 185 (2013) 385-394.

[40] A. Bergström, T.H. Skov, M.I. Bahl, H.M. Roager, L.B. Christensen, K.T. Ejlerskov, et al., Establishment of intestinal microbiota during early life: a longitudinal, explorative study of a large cohort of Danish infants, Appl. Environ. Microbiol. 80 (2014) 2889-2900.

[41] E. Biagi, L. Nylund, M. Candela, R. Ostan, L. Bucci, E. Pini, et al., Through ageing, and beyond: gut microbiota and inflammatory status in seniors and centenarians, PLoS One 5 (2010) e10667.

[42] F. Wang, T. Yu, G. Huang, D. Cai, X. Liang, H. Su, et al., Gut microbiota community and its assembly associated with age and diet in Chinese centenarians, J. Microbiol. Biotechnol. 24 (2014).

[43] P. Wacklin, J. Tuimala, J. Nikkilä, T. Sebastian, H. Mäkivuokko, N. Alakulppi, et al., Faecal microbiota composition in adults is associated with the FUT2 gene determining the secretor status, PLoS One 9 (2014) e94863.

[44] M. Ellekilde, L. Krych, C.H.F. Hansen, M.R. Hufeldt, K. Dahl, L.H. Hansen, et al. Characterization of the gut microbiota in leptin deficient obese mice correlation to inflammatory and diabetic parameters, Res. Vet. Sci. 96 (2014) $241-250$.

[45] H. Zhang, J.B. Sparks, S.V. Karyala, R. Settlage, X.M. Luo, Host adaptive immunity alters gut microbiota, ISME J. 9 (2015) 770-781.

[46] T.L.A. Nguyen, S. Vieira-Silva, A. Liston, J. Raes, How informative is the mouse for human gut microbiota research? Dis. Model Mech. 8 (2015) 1-16.

[47] D.E. Roopchand, R.N. Carmody, P. Kuhn, K. Moskal, P. Rojas-Silva, P.J. Turnbaugh, et al., Dietary polyphenols promote growth of the gut bacterium Akkermansia muciniphila and attenuate high fat diet-induced metabolic syndrome, Diabetes (2015).

[48] F.F. Anhê, D. Roy, G. Pilon, S. Dudonné, S. Matamoros, T.V. Varin, et al., A polyphenol-rich cranberry extract protects from diet-induced obesity, insulin resistance and intestinal inflammation in association with increased Akkermansia spp. population in the gut microbiota of mice, Gut 64 (2015) 872-883. 
[49] A. Everard, V. Lazarevic, M. Derrien, M. Girard, G.G. Muccioli, A.M. Neyrinck, et al., Responses of gut microbiota and glucose and lipid metabolism to prebiotics in genetic obese and diet-induced leptin-resistant mice, Diabetes 60 (2011) 2775-2786.

[50] D. Reid, L. Eller, J. Nettleton, R. Reimer, Postnatal prebiotic fibre intake mitigates some detrimental metabolic outcomes of early overnutrition in rats, Eur. J. Nutr. (2015) 1-11.

[51] A. Chaplin, P. Parra, F. Serra, A. Palou, Conjugated linoleic acid supplementation under a high-fat diet modulates stomach protein expression and intestinal microbiota in adult mice, PLoS One 10 (2015) e0125091.

[52] K. Andersson, U. Axling, J. Xu, K. Swärd, S. Ahrné, G. Molin, et al., Diverse effects of oats on cholesterol metabolism in C57BL/6 mice correlate with expression of hepatic bile acid-producing enzymes, Eur. J. Nutr. 52 (2013) 1755-1769.

[53] T. Sybille, Z. June, K. Michael, M. Roy, L.M. Maria, The intestinal microbiota in aged mice is modulated by dietary resistant starch and correlated with improvements in host responses, FEMS Microbiol. Ecol. 83 (2013) 299-309.

[54] E.P. Halmos, C.T. Christophersen, A.R. Bird, S.J. Shepherd, P.R. Gibson, J.G. Muir, Diets that differ in their FODMAP content alter the colonic luminal microenvironment, Gut 64 (2015) 93-100.

[55] Y. Zhong, M. Nyman, F. Fåk, Modulation of gut microbiota in rats fed high-fat diets by processing whole-grain barley to barley malt, Mol. Nutr. Food Res. (2015) n/a-n/a.

[56] C. Gómez-Gallego, M.C. Collado, T. Ilo, U.-M. Jaakkola, M.J. Bernal, M.J. Periago, et al., Infant formula supplemented with polyamines alters the intestinal microbiota in neonatal BALB/cOlaHsd mice, J. Nutr. Biochem. 23 (2012) 1508-1513.

[57] C. Gómez-Gallego, M.C. Collado, G. Pérez, T. Ilo, U.-M. Jaakkola, M.J. Bernal, et al., Resembling breast milk: influence of polyamine-supplemented formula on neonatal BALB/cOlaHsd mouse microbiota, Br. J. Nutr. 111 (2014) $1050-1058$.

[58] H. Song, Q. Chu, F. Yan, Y. Yang, W. Han, X. Zheng, Red pitaya betacyanins protects from diet-induced obesity, liver steatosis and insulin resistance in association with modulation of gut microbiota in mice, J. Gastroenterol. Hepatol. (2015) (n/a-n/a).

[59] J. Alard, V. Lehrter, M. Rhimi, I. Mangin, V. Peucelle, A.-L. Abraham, et al., Beneficial metabolic effects of selected probiotics on diet-induced obesity and insulin resistance in mice are associated with improvement of dysbiotic gut microbiota, Environ. Microbiol. (2015) (n/a-n/a).

[60] J. Yang, L.B. Bindels, R.R. Segura Munoz, I. Martínez, J. Walter, A.E. Ramer-Tait, et al., Disparate metabolic responses in mice fed a high-fat diet supplemented with maize-derived non-digestible feruloylated oligo- and polysaccharides are linked to changes in the gut microbiota, PLoS One 11 (2016) e0146144.

[61] J.-H. Wang, S. Bose, G.-C. Kim, S.-U. Hong, J.-H. Kim, J-e Kim, et al., Flos Lonicera ameliorates obesity and associated endotoxemia in rats through modulation of gut permeability and intestinal microbiota, PLoS One 9 (2014) e86117.

[62] J.-H. Wang, S. Bose, H.-G. Kim, K.-S. Han, H. Kim, Fermented Rhizoma Atractylodis Macrocephalae alleviates high fat diet-induced obesity in association with regulation of intestinal permeability and microbiota in rats, Sci. Rep. 5 (2015).

[63] C.-J. Chang, C.-S. Lin, C.-C. Lu, J. Martel, Y.-F. Ko, D.M. Ojcius, et al., Ganoderma lucidum reduces obesity in mice by modulating the composition of the gut microbiota, Nat. Commun. 6 (2015).

[64] G. Jakobsdottir, J. Xu, G. Molin, S. Ahrné, M. Nyman, High-fat diet reduces the formation of butyrate, but increases succinate, inflammation, liver fat and cholesterol in rats, while dietary fibre counteracts these effects, PLoS One 8 (2013) e80476.

[65] J. Baldwin, B. Collins, P.G. Wolf, K. Martinez, W. Shen, C.-C. Chuang, et al., Table grape consumption reduces adiposity and markers of hepatic lipogenesis and alters gut microbiota in butter fat-fed mice, J. Nutr. Biochem. (2015).

[66] A. Everard, C. Belzer, L. Geurts, J.P. Ouwerkerk, C. Druart, L.B. Bindels, et al., Cross-talk between Akkermansia muciniphila and intestinal epithelium controls diet-induced obesity, Proc. Natl. Acad. Sci. U. S. A. 110 (2013) 9066-9071.

[67] N.-R. Shin, J.-C. Lee, H.-Y. Lee, M.-S. Kim, T.W. Whon, M.-S. Lee, et al., An increase in the Akkermansia spp. population induced by metformin treatment improves glucose homeostasis in diet-induced obese mice, Gut 63 (2014) 727-735.

[68] H. Lee, G. Ko, Effect of metformin on metabolic improvement and gut microbiota, Appl. Environ. Microbiol. 80 (2014) 5935-5943.

[69] S. Sands, S. Tsau, T. Yankee, B. Parker, A. Ericsson, S. LeVine, The effect of omeprazole on the development of experimental autoimmune encephalomyelitis in C57BL/6J and SJL/J mice, BMC Res. Notes 7 (2014) 605.

[70] DE. Freedberg, NC. Toussaint, SP. Chen, AJ. Ratner, S. Whittier, TC Wang, et al. Proton pump inhibitors alter specific taxa in the human gastrointestinal microbiome: a crossover trial. Gastroenterology.149:883-5.e9.

[71] Y.R. Nobel, L.M. Cox, F.F. Kirigin, N.A. Bokulich, S. Yamanishi, I. Teitler, et al., Metabolic and metagenomic outcomes from early-life pulsed antibiotic treatment, Nat. Commun. 6 (2015).

[72] G. Dubourg, J.-C. Lagier, F. Armougom, C. Robert, G. Audoly, L. Papazian, et al., High-level colonisation of the human gut by Verrucomicrobia following broad-spectrum antibiotic treatment, Int. J. Antimicrob. Agents 41 (2013)
$149-155$.

[73] A. Caputo, G. Dubourg, O. Croce, S. Gupta, C. Robert, L. Papazian, et al., Wholegenome assembly of Akkermansia muciniphila sequenced directly from human stool, Biol. Direct 10 (2015) 5.

[74] A. Vrieze, C. Out, S. Fuentes, L. Jonker, I. Reuling, R.S. Kootte, et al., Impact of oral vancomycin on gut microbiota, bile acid metabolism, and insulin sensitivity, J. Hepatol. 60 (2014) 824-831.

[75] M. Ferrer, V.A.P. Martins dos Santos, S.J. Ott, A. Moya, Gut microbiota disturbance during antibiotic therapy, Gut Microbes 5 (2013) 64-70.

[76] E. Hernández, R. Bargiela, M.S. Diez, A. Friedrichs, A.E. Pérez-Cobas, M.J. Gosalbes, et al., Functional consequences of microbial shifts in the human gastrointestinal tract linked to antibiotic treatment and obesity, Gut Microbes 4 (2013) 306-315.

[77] C.H.F. Hansen, L. Krych, D.S. Nielsen, F.K. Vogensen, L.H. Hansen, S.J. Sørensen, et al., Early life treatment with vancomycin propagates Akkermansia muciniphila and reduces diabetes incidence in the NOD mouse, Diabetologia 55 (2012) 2285-2294.

[78] P.D. Cani, J. Amar, M.A. Iglesias, M. Poggi, C. Knauf, D. Bastelica, et al. Metabolic endotoxemia initiates obesity and insulin resistance, Diabetes 56 (2007) 1761-1772.

[79] M. Rosenbaum, R. Knight, R.L. Leibel, The gut microbiota in human energy homeostasis and obesity, Trends Endocrinol. Metabolism 26 (2015) 493-501.

[80] V.K. Ridaura, J.J. Faith, F.E. Rey, J. Cheng, A.E. Duncan, A.L. Kau, et al., Gut microbiota from twins discordant for obesity modulate metabolism in mice, Science 341 (2013).

[81] F. Bäckhed, H. Ding, T. Wang, L.V. Hooper, G.Y. Koh, A. Nagy, et al., The gut microbiota as an environmental factor that regulates fat storage, Proc. Nat. Acad. Sci. U. S. A. 101 (2004) 15718-15723.

[82] A. Vrieze, E. Van Nood, F. Holleman, J. Salojärvi, RS. Kootte, JFWM. Bartelsman, et al. Transfer of intestinal microbiota from lean donors increases insulin sensitivity in individuals with metabolic syndrome. Gastroenterology.143:913-6.e7.

[83] M. Cox Laura, S. Yamanishi, J. Sohn, V. Alekseyenko Alexander, M. Leung Jacqueline, I. Cho, et al. Altering the intestinal microbiota during a critical developmental window has lasting metabolic consequences. Cell.158: $705-721$.

[84] A.P. Liou, M. Paziuk, J.-M. Luevano, S. Machineni, P.J. Turnbaugh, L.M. Kaplan, Conserved shifts in the gut microbiota due to gastric bypass reduce host weight and adiposity, Sci. Transl. Med. 5 (2013) 178-241.

[85] H. Zhang, J.K. DiBaise, A. Zuccolo, D. Kudrna, M. Braidotti, Y. Yu, et al., Human gut microbiota in obesity and after gastric bypass, Proc. Natl. Acad. Sci. U. S. A. 106 (2009) 2365-2370.

[86] E. Org, B.W.W. Parks, J.W.J. Joo, B. Emert, W. Schwartzman, E.Y. Kang, et al. Genetic and environmental control of host-gut microbiota interactions, Genome Res. 25 (2015) 1558-1569.

[87] C. Chevalier, O. Stojanović, J. Colin Didier, N. Suarez-Zamorano, V. Tarallo, C. Veyrat-Durebex, et al., Gut microbiota orchestrates energy homeostasis during cold, Cell. 163 (2015) 1360-1374.

[88] Y. Zhong, N. Marungruang, F. Fåk, M. Nyman, Effects of two whole-grain barley varieties on caecal SCFA, gut microbiota and plasma inflammatory markers in rats consuming low- and high-fat diets, Br. J. Nutr. (2015) FirstView:1-13.

[89] F. Fåk, G. Jakobsdottir, E. Kulcinskaja, N. Marungruang, C. Matziouridou, U. Nilsson, et al., The physico-chemical properties of dietary fibre determine metabolic responses, short-chain fatty acid profiles and gut microbiota composition in rats fed low- and high-fat diets, PLoS One 10 (2015) e0127252.

[90] M.K. Hamilton, G. Boudry, D.G. Lemay, H.E. Raybould, Changes in intestinal barrier function and gut microbiota in high-fat diet-fed rats are dynamic and region dependent, Am. J. Physiol. Gastrointest. Liver Physiol. 308 (2015) G840-G851.

[91] N. Carmody Rachel, K. Gerber Georg, M. Luevano Jesus Jr., M. Gatti Daniel L. Somes, L. Svenson Karen, et al., Diet dominates host genotype in shaping the murine gut microbiota, Cell Host Microbe 17 (2015) 72-84.

[92] C.L.J. Karlsson, J. Önnerfält, J. Xu, G. Molin, S. Ahrné, K. Thorngren-Jerneck, The microbiota of the gut in preschool children with normal and excessive body weight, Obesity 20 (2012) 2257-2261.

[93] T.F.S. Teixeira, Ł.M. Grześkowiak, S. Salminen, K. Laitinen, J. Bressan, MdC. Gouveia Peluzio, Faecal levels of Bifidobacterium and Clostridium coccoides but not plasma lipopolysaccharide are inversely related to insulin and HOMA index in women, Clin. Nutr. 32 (2013) 1017-1022.

[94] M. Remely, I. Tesar, B. Hippe, S. Gnauer, P. Rust, A.G. Haslberger, Gut microbiota composition correlates with changes in body fat content due to weight loss, Benef. Microbes 6 (2015) 431-439.

[95] J.S. Escobar, B. Klotz, B. Valdes, G. Agudelo, The gut microbiota of Colombians differs from that of Americans, Eur. Asians. BMC Microbiol 14 (2014).

[96] L.K. Brahe, E. Le Chatelier, E. Prifti, N. Pons, S. Kennedy, T. Hansen, et al. Specific gut microbiota features and metabolic markers in postmenopausal women with obesity, Nutr. Diabetes 5 (2015) e159.

[97] A. Santacruz, M.C. Collado, L. García-Valdés, M.T. Segura, J.A. Martín-Lagos T. Anjos, et al., Gut microbiota composition is associated with body weight, weight gain and biochemical parameters in pregnant women, Br. J. Nutr. 104 (2010) 83-92.

[98] M.C. Collado, E. Isolauri, K. Laitinen, S. Salminen, Effect of mother's weight on 
infant's microbiota acquisition, composition, and activity during early infancy: a prospective follow-up study initiated in early pregnancy, Am. J. Clin. Nutr. 92 (2010) 1023-1030.

[99] J. Qin, Y. Li, Z. Cai, S. Li, J. Zhu, F. Zhang, et al., A metagenome-wide association study of gut microbiota in type 2 diabetes, Nature 490 (2012) 55-60.

[100] K. Forslund, F. Hildebrand, T. Nielsen, G. Falony, E. Le Chatelier, S. Sunagawa, et al., Disentangling type 2 diabetes and metformin treatment signatures in the human gut microbiota, Nature 528 (2015) 262-266.

[101] Å. Håkansson, N. Tormo-Badia, A. Baridi, J. Xu, G. Molin, M.L. Hagslätt, et al. Immunological alteration and changes of gut microbiota after dextran sulfate sodium (DSS) administration in mice, Clin. Exp. Med. 15 (2015) 107-120.

[102] D.H. Reikvam, M. Derrien, R. Islam, A. Erofeev, V. Grcic, A. Sandvik, et al., Epithelial-microbial crosstalk in polymeric Ig receptor deficient mice, Eur. J. Immunol. 42 (2012) 2959-2970.

[103] D. Berry, C. Schwab, G. Milinovich, J. Reichert, K. Ben Mahfoudh, T. Decker, et al., Phylotype-level 16S rRNA analysis reveals new bacterial indicators of health state in acute murine colitis, ISME J. 6 (2012) 2091-2106.

[104] D. Berry, O. Kuzyk, I. Rauch, S. Heider, C. Schwab, E. Hainzl, et al., Intestinal microbiota signatures associated with inflammation history in mice experiencing recurring colitis, Front. Microbiol. 6 (2015).

[105] Kang C-S, M. Ban, E.-J. Choi, H.-G. Moon, J.-S. Jeon, D.-K. Kim, et al., Extracellular vesicles derived from gut microbiota, especially Akkermansia muciniphila, protect the progression of dextran sulfate sodium-induced colitis, PLoS One 8 (2013) e76520.

[106] M. Rajilic-Stojanovic, F. Shanahan, F. Guarner, W.M. de Vos, Phylogenetic analysis of dysbiosis in ulcerative colitis during remission, Inflamm. Bowel Dis. 19 (2013) 481-488.

[107] A. Swidsinski, Y. Dörffel, V. Loening-Baucke, F. Theissig, J.C. Rückert, M. Ismail, et al., Acute appendicitis is characterised by local invasion with Fusobacterium nucleatum/necrophorum, Gut 60 (2011) 34-40.

[108] L.M. Loonen, E.H. Stolte, M.T. Jaklofsky, M. Meijerink, J. Dekker, P. van Baarlen, et al., REG3 [gamma]-deficient mice have altered mucus distribution and increased mucosal inflammatory responses to the microbiota and enteric pathogens in the ileum, Mucosal Immunol. 7 (2014) 939-947.

[109] P. Van den Abbeele, P. Gérard, S. Rabot, A. Bruneau, S. El Aidy, M. Derrien, et al., Arabinoxylans and inulin differentially modulate the mucosal and luminal gut microbiota and mucin-degradation in humanized rats, Environ. Microbiol. 13 (2011) 2667-2680.

[110] A. Earle Kristen, G. Billings, M. Sigal, S. Lichtman Joshua, C. Hansson Gunnar, E. Elias Joshua, et al., Quantitative imaging of gut microbiota spatial organization, Cell Host Microbe 18 (2015) 478-488.

[111] N. Ijssennagger, C. Belzer, G.J. Hooiveld, J. Dekker, S.W.C. van Mil, M. Müller, et al., Gut microbiota facilitates dietary heme-induced epithelial hyperproliferation by opening the mucus barrier in colon, Proc. Natl. Acad. Sci. U. S. A. 112 (2015) 10038-10043.

[112] S. Lukovac, C. Belzer, L. Pellis, B.J. Keijser, W.M. de Vos, R.C. Montijn, et al.,
Differential modulation by Akkermansia muciniphila and Faecalibacterium prausnitzii of host peripheral lipid metabolism and histone acetylation in mouse gut organoids, mBio 5 (2014) e01438-e01514.

[113] K.L. Alexander, S.R. Targan, C.O. Elson, Microbiota activation and regulation of innate and adaptive immunity, Immunol. Rev. 260 (2014) 206-220.

[114] AJ. Macpherson, Y. Köller, KD. McCoy. The bilateral responsiveness between intestinal microbes and IgA. Trends Immunol. 36:460-470.

[115] A. Mathias, B. Pais, L. Favre, J. Benyacoub, B. Corthésy, Role of secretory IgA in the mucosal sensing of commensal bacteria, Gut Microbes 5 (2014) 688-695.

[116] A.L. Kau, J.D. Planer, J. Liu, S. Rao, T. Yatsunenko, I. Trehan, et al., Functional characterization of IgA-targeted bacterial taxa from undernourished Malawian children that produce diet-dependent enteropathy, Sci. Transl. Med. 7 (2015) 276-324.

[117] J. Reunanen, V. Kainulainen, L. Huuskonen, N. Ottman, C. Belzer, H. Huhtinen, et al., Akkermansia muciniphila adheres to enterocytes and strengthens the integrity of epithelial cell layer, Appl. Environ. Microbiol. (2015).

[118] B.P. Ganesh, R. Klopfleisch, G. Loh, M. Blaut, Commensal Akkermansia muciniphila exacerbates gutiInflammation in Salmonella Typhimurium-infected gnotobiotic mice, PLoS One 8 (2013) e74963x.

[119] M. Kankainen, L. Paulin, S. Tynkkynen, I. von Ossowski, J. Reunanen, P. Partanen, et al., Comparative genomic analysis of Lactobacillus rhamnosus GG reveals pili containing a human- mucus binding protein, Proc. Natl. Acad. Sci. U. S. A. 106 (2009) 17193-17198.

[120] H. Earley, G. Lennon, A. Balfe, M. Kilcoyne, M. Clyne, L. Joshi, et al., A preliminary study examining the binding capacity of Akkermansia muciniphila and Desulfovibrio spp., to colonic mucin in health and ulcerative colitis, PLoS One 10 (2015) e0135280.

[121] M.W.J. van Passel, R. Kant, E.G. Zoetendal, C.M. Plugge, M. Derrien, S.A. Malfatti, et al., The Genome of Akkermansia muciniphila, a dedicated intestinal mucin degrader, and its use in exploring intestinal metagenomes, PLoS One 6 (2011) e16876.

[122] S.F. Clarke, E.F. Murphy, O. O'Sullivan, A.J. Lucey, M. Humphreys, A. Hogan, et al., Exercise and associated dietary extremes impact on gut microbial diversity, Gut 63 (2014) 1913-1920.

[123] B.-S. Kim, M-y Song, H. Kim, The anti-obesity effect of Ephedra sinica through modulation of gut microbiota in obese Korean women, J. Ethnopharmacol. 152 (2014) 532-539.

[124] M. Remely, B. Hippe, I. Geretschlaeger, S. Stegmayer, I. Hoefinger, A. Haslberger, Increased gut microbiota diversity and abundance of Faecalibacterium prausnitzii and Akkermansia after fasting: a pilot study, Wien Klin. Wochenschr. (2015) 1-5.

[125] X. Zhang, D. Shen, Z. Fang, Z. Jie, X. Qiu, C. Zhang, et al., Human gut microbiota changes reveal the progression of glucose intolerance, PLoS One 8 (2013) e71108. 